\title{
$\operatorname{cs}^{5}$
}

\section{How do they get here?: Paths into physics education research}

\author{
Ramón S. Barthelemy \\ Mallinson Institute for Science Education, Western Michigan University, Kalamazoo, Michigan 49008, USA \\ Charles Henderson \\ Department of Physics and Mallinson Institute for Science Education, Western Michigan University, Kalamazoo, \\ Michigan 49008, USA \\ Megan L. Grunert \\ Department of Chemistry and Mallinson Institute for Science Education, Western Michigan University, \\ Kalamazoo, Michigan 49008, USA
}

(Received 29 April 2013; published 24 July 2013)

\begin{abstract}
Physics education research (PER) is a relatively new and rapidly growing area of Ph.D. specialization. To sustain the field of PER, a steady pipeline of talented scholars needs to be developed and supported. One aspect of building this pipeline is understanding how students come to graduate and postdoctoral work in PER and what their career goals are. This paper presents the first study on the experiences and career pathways of students in PER. Data were collected through open-ended interviews with 13 graduate students and postdoctoral scholars in PER. Results show that many of these PER graduate students and postdoctoral scholars were not aware of PER as undergraduates. PER graduate students that were aware of PER as undergraduates chose to study PER as they were applying to graduate schools. The graduate school experiences of the interviewees were overwhelmingly positive, with participants reporting a positive climate that was facilitated by communicative and productive relationships with their advisors. However, some participants reported concerns about the acceptance of PER within some departments, including open hostility towards the field. The majority of participants were interested in pursuing a career as a university faculty member, with more participants preferring a position at a research-intensive university. These results suggest that a further large-scale study of graduate students in PER may be able to highlight the field as being a leader in student mentoring and community development while collecting important demographic information that could show PER to have more gender diversity than other subfields of physics.
\end{abstract}

DOI: 10.1103/PhysRevSTPER.9.020107

PACS numbers: 01.40.Fk

\section{INTRODUCTION}

Physics education research (PER) is one of the most recent areas of specialization to be added to the U.S. Departments of Physics. The history of PER in the U.S. dates back to the creation of the American Association of Physics Teachers in 1930, with the first PER research groups coming a few decades later [1,2]. Currently, there are PER scholars in almost every state in the U.S., with graduate programs conferring Ph.D.'s in physics, education, and other fields for work in PER [3]. Though the field has become widespread in the past few decades, including annual conferences that began in 1997, it is still young and evolving in comparison to many other fields of physics [1]. The experiences and career paths of scholars in PER are understudied and undocumented. For the field to continue

Published by the American Physical Society under the terms of the Creative Commons Attribution 3.0 License. Further distribution of this work must maintain attribution to the author( $(s)$ and the published article's title, journal citation, and DOI. progressing, a strong pipeline of future scholars must be recruited, mentored, and prepared for careers in PER. One important aspect of this pipeline maintenance is understanding how graduate students come to the field and what their experiences are within the community of PER.

The study of how and why students come to PER and their experiences in graduate school is important not only for PER but also for educational research in other science, technology, engineering, and mathematics disciplines. Currently, no research has been conducted about the pathways or experiences of graduate students in PER or discipline-based education research (DBER) fields. Recently the National Research Council released a report about the state of DBER [2]. The report, developed by a panel of experts from various DBER and related fields, noted this lack of research on graduate education in DBER and identified graduate education in DBER as an important area for research:

"Graduate education in DBER is itself ripe for further study and exploration. As DBER fields mature, a growing number of researchers have been trained in DBER 
graduate programs and are now in academic positions. Now is the time to ask questions, not only about the outcomes of a DBER graduate education (job placement, research productivity/contributions, etc.), but also about best practices for educating graduate students in DBER. These studies would be valuable additions to the literature, and could help to guide the development of programs in newer fields such as astronomy, biology, and geoscience education." (Ref. [2], p. 34)

Thus, the results of this study will be important not only for the field of PER but also for DBER fields in other science and engineering disciplines. The exploratory nature of this study is appropriate for a new area of investigation and can help build the foundation for future studies.

\section{GOALS AND RESEARCH QUESTIONS}

The overall goal of this project was to explore the experiences and career trajectories of students and scholars in PER. This paper addresses the following research questions through interviews with 13 graduate students and postdoctoral scholars in PER: (1) When and how did these participants discover PER? (2) When and why did these participants choose to do work in PER? (3) What were these participants' experiences within PER? (4) What are the career goals of these participants?

\section{METHODOLOGY}

As discussed above, no prior research has been done on graduate students in PER or other DBER fields. Thus, this study took an exploratory perspective and sought to capture a wide breadth of data from the population of interest (graduate students and postdoctoral researchers in PER). For an exploratory study, it is common to use qualitative research methods that allow for the generation of emergent ideas from rich data sets $[4,5]$. The research methods are discussed in detail below.

\section{A. Data collection: In-depth interviews}

The data collection methodology used in this study was open-ended interviews [4,5]. Marshall and Rossman [4] suggest that open-ended interviews allow participants to guide the conversation and explore topics important to them. This approach lends itself well to an exploratory study because it allows participants to reveal experiences and ideas important to them that may not have been considered by the researcher. Consequently, interviews were constructed to allow the participants to do most of the talking while the interviewer listened carefully to identify where further exploration was needed. All interviews were conducted by the first author.

Before participants were interviewed, they filled out a demographics form. This included questions about their identities and education to give the interviewer some information about them before the first meeting. A copy of the demographics form is attached in the Appendix. The interview protocol was a list of themed questions to be discussed through the conversational interviews. This protocol was designed using five open-ended questions as suggested by Creswell [5]. Open-ended questions are broad questions that allow participants to respond in a wide array of ways. This allows the participant to choose to discuss what is important to them, but central to a theme of interest to the researcher. A final sixth question was added to leave all interviews on a positive topic. This strategy was adopted from a study of physics faculty where the author left all faculty members discussing a positive aspect of their careers at the end of each interview [6]. The themed questions that were used as an interview protocol are listed below.

(1) Tell me about the pathways that led you to physics.

(2) Tell me about your course work experiences.

(3) What kinds of interactions did you have with the other graduate students in your department?

(4) How did you end up choosing your current advisor?

(5) What drew you towards your research subfield?

(6) What accomplishments are you most proud of so far?

Given the exploratory goals of this study, the interviewer often followed other avenues of investigation that were brought up by the interviewee and appeared fruitful. To fully explore topics that seemed of interest to participants the interviewer would often use probing questions, such as "Tell me more about when you switched into PER."

To conduct the interviews, the first author visited three universities. Two of the visits lasted one week and included his entering into the department for the duration by going to meetings and listening to colloquia. This was not possible at one of the campuses where the site visit lasted only a weekend. Before the interviews began, rapport was built by small side conversations while walking to the interview locations, interactions during department colloquia and meetings, or through introductions by faculty members. Marshall and Rossman [4] argue that rapport with participants can help produce richer data. Rapport building was done before every interview and at every site visit [4]. Interviews ranged from 30 minutes to over an hour.

The interviewer continually took effort to keep his own experiences from biasing his questions and to ensure that the questions being asked evolved from the interactions with the participants and not his own experiences as a graduate student in PER. He did this by listening to interviews after they were conducted and questioning how and why he reacted to the interviewee responses. He memoed about his reactions to see if they derived from the responses or his experiences. He used this exercise to change how he reacted to further interviewee responses. Interviews were transcribed verbatim, resulting in an average of 25 pages of text to be analyzed. Finally, all participants were given the 
opportunity to review the transcripts and add clarifications or make any omissions or changes. This allowed them to have further voice in the process of data analysis and ensured that the transcripts being used were accurate reflections of their experiences.

To ensure anonymity within the relatively small PER community, interview quotes and other results will be shared in aggregate without pseudonyms. Each presented quote is from one participant. The only edits to the quotes that have been made were the removal of "umms" and "ahhs" that were pauses and did not add context or data, and the removal of specific nouns that were replaced with more general terms in brackets. In this vein, the gender of participants will also be obscured. Instances of she or he and her or his will be replaced with she and her, respectively.

\section{B. Participant recruitment and demographics}

Participants were recruited from three large public research institutions in the U.S. with well-established graduate programs in PER. Currently, most PER programs are housed in research-intensive universities where departments have large physics and education faculties. This makes the choice of these kinds of universities a suitable starting point for research into the educational pathways and experiences of students and postdoctoral scholars in PER.

Potential participant Email lists were constructed by contacting research group leaders in PER at the respective universities. This generated a complete population of all graduate students and postdoctoral researchers at these three universities, all of whom were sent an invitation to participate in the study. Overall, 19 people were invited to participate in the study ( 9 men, 10 women) with 13 accepting ( 5 men, 8 women). To be part of the study, participants had to either be pursuing a Ph.D. with a research focus in PER $(N=8)$ or be in a postdoctoral position as a PER researcher $(N=5)$. They could be in a department of physics $(N=11)$ or school of education $(N=2)$. The race of participants will not be discussed to ensure anonymity of participants due to the small size of the PER community, but most respondents reported identifying as white. Of the participating postdoctoral scholars, two were new to PER and had not conducted research in PER during their graduate programs. The demographics of the participants are summarized in Table I.

These participants represented an array of students and postdoctoral researchers pursuing Ph.D.'s in physics and education with a research track in PER. The representative nature of this sample is hard to determine because currently there exists no demographic information on students in PER. Because these participants were drawn from research-intensive universities with well-established programs in PER, their experiences may not be able to be expanded to non-research-intensive schools or schools with newer or smaller PER programs. Nevertheless,
TABLE I. Participant demographics.

\begin{tabular}{llc}
\hline \hline Demographic & & Number \\
\hline University & University of X & 8 \\
& University of Y & 4 \\
& University of Z & 1 \\
Ph.D. track & Ph.D. in physics & 11 \\
& Ph.D. in education & 2 \\
Academic stage & Graduate student & 9 \\
& Postdoctoral scholar & 4 \\
& Graduate research in PER & 11 \\
Sex & Female & 8 \\
& Male & 5 \\
& Total participants & 13 \\
\hline \hline
\end{tabular}

research-intensive universities with well-established programs in PER are important producers of PER researchers. Understanding the graduate student and postdoctoral experiences at these schools is important and can offer a starting point for further work at other types of institutions.

\section{Analysis}

All interviews were audio recorded, transcribed, and qualitatively coded through emergent coding by the first author, which was validated by the second and third authors by discussing the coding process of the first author and reviewing transcript excerpts together [7]. Coding was an emergent process, in that continual readings of the data brought forward actions and experiences of the participants that would take form in a code [7]. Analysis began as soon as data were taken. After each transcription was completed, it was first analyzed line by line to look for actions and experiences of the participants to gain an overall understanding of their academic lives [7]. As each code emerged, it became part of a code book. When subsequent interviews yielded new codes, the previous transcripts were reread to see if the new codes applied. This is called the constant comparative method and required the first author to continually reread all transcripts and review data that had been taken while collecting more [5]. This approach helped immerse the researcher in the data, which aids in the analysis process. Ultimately the code book consisted of 110 codes. A listing of the most common codes and themes is shown in Table II. Not all of the codes and themes in Table II are discussed within this paper.

Some codes were then combined to form emergent themes. For example, in the excerpt below the code interests outside of physics was applied. This code and example was then later included in the emergent theme breadth of experience. This code was included in that emergent theme because it illustrated an experience the participant had outside of physics while also demonstrating the breadth of activities they had experienced. Breadth of experience 
TABLE II. Most frequently used codes.

\begin{tabular}{|c|c|c|c|}
\hline & & No. & Description \\
\hline \multirow[t]{2}{*}{ Code } & $\begin{array}{l}\text { Support-Professors } \\
\text { or advisors }\end{array}$ & 43 & $\begin{array}{l}\text { Applied when a participant described } \\
\text { positive interactions with faculty that } \\
\text { supported their education }\end{array}$ \\
\hline & $\begin{array}{l}\text { Worked on home- } \\
\text { work with other } \\
\text { undergraduates }\end{array}$ & 18 & $\begin{array}{l}\text { Applied when participants described } \\
\text { collaborating on undergraduate } \\
\text { homework }\end{array}$ \\
\hline
\end{tabular}

Science in the home 16 Applied when participants described science experiences in the home

Undergraduate research

Research advisorCommunication good

Physics-

Noneducation

research

Career-Research

intensive

Scientist in family

PER why they

are interested

Breadth-Interests

outside of physics

Breadth-Jobs

outside of physics

Discouragement

Impact or help people

PER how they found out about Greatest accomplishment

Guidance

Location of graduate school

Science experience in high school

PER as apart of physics
16 Applied when participant described doing research as an undergrad

14 Applied when participant described productive and pleasant communication with their advisor

13 Applied when participant described doing noneducation research

12 Applied when participant described research universities

12 Applied when participant described having a scientist in their family

12 Applied when participant described why they chose PER

11 Applied when participants described having an interest beyond physics

11 Applied when participant described having a job outside the field of physics

10 Applied when participant described being discouraged

10 Applied when participant described wanting to have an impact on the world or students

10 Applied when participant described how they found out about PER

9 Applied when participant described their greatest accomplishment

9 Applied when participant described having guidance academically or professionally

9 Applied when participant described the importance of their graduate school's location

9 Applied when participant described having a science experience in high school

9 Applied when participant described PER as being a part of physics
Example from interviews

I always felt they had my best interests and that they are trying to help me succeed in not only in graduate school but umm life in general and in my projects....

... you come in and you can work on your problems together and sometimes I felt like anybody could do this degree if they're willing to come into this room and work with other people. So um, as as a child my dad uh was a teacher and did a lot of science stuff and so we did a lot of science projects together just for fun! ... midway through uh I got involved in undergraduate research uh so I was doing um atomic molecular and optical physics... . I could communicate with him very well.

... so a little condensed matter research and I also had an REU... .

... doing physics ED research, umm at like a Rl university.

... both my parents had umm graduate degrees in engineering.

I felt like I had a chance to make a bigger impact than being a science writer.

I chose the college that I did because they had a creative writing major, which was unusual.

I was a software engineer.

It was one of the most humiliating experiences in my life. I get up there and he asks me to explain what I'm working on and I start talking about it and he interrupts me after two minutes. I enjoyed being in the classroom, helping students um that, the-, the few times that people would suddenly get something that they hadn't got before was really fun.

So I went to a talk that he gave that sorta on education research....

...they [students] think I'm a good teacher and I that like that makes me happy because that's something I can value... .

It was kinda expected that I went to college. With my parents had been there and emphasizing it was something I was supposed to do. ... it came down to where I felt I was going to be the most comfortable and most concentrated on my work. And I just thought I would be too distracted in the city.

I took a physics class my senior year and really enjoyed it.

you know that's a part of my identity is physics as a physicist... 
TABLE II. (Continued)

\begin{tabular}{|c|c|c|c|c|}
\hline & & No. & Description & Example from interviews \\
\hline & $\begin{array}{l}\text { Programs or student } \\
\text { groups }\end{array}$ & 9 & $\begin{array}{l}\text { Applied when participant described being } \\
\text { apart of a student group }\end{array}$ & $\begin{array}{l}\text { Also I really got involved with the Christian } \\
\text { graduate student group here. }\end{array}$ \\
\hline & $\begin{array}{l}\text { Research advisor- } \\
\text { Communication bad }\end{array}$ & 9 & $\begin{array}{l}\text { Applied when participant described } \\
\text { unproductive communication with an } \\
\text { advisor }\end{array}$ & $\begin{array}{l}\text {... its another reason Ifelt less inclined to go to } \\
\text { him when I had a question. }\end{array}$ \\
\hline & $\begin{array}{l}\text { Worked on } \\
\text { homework with } \\
\text { other graduates }\end{array}$ & 9 & $\begin{array}{l}\text { Applied when participant described working } \\
\text { on homework with other graduate students }\end{array}$ & $\begin{array}{l}\text { There were a couple of students I could work } \\
\text { with and had some good working relationships } \\
\text { with... }\end{array}$ \\
\hline & $\begin{array}{l}\text { Career-Teaching } \\
\text { intensive }\end{array}$ & 8 & $\begin{array}{l}\text { Applied when participant brought up } \\
\text { teaching universities }\end{array}$ & $\begin{array}{l}\text { I don't imagine myself being in a position like I } \\
\text { have a small liberal arts college where I have } \\
\text { to teach four classes... }\end{array}$ \\
\hline & Community & 8 & $\begin{array}{l}\text { Applied when participant described } \\
\text { community issues }\end{array}$ & $\begin{array}{l}\text { Umm so I didn't have that community around } \\
\text { me. }\end{array}$ \\
\hline \multirow[t]{8}{*}{ Theme } & Community & 91 & $\begin{array}{l}\text { Codes such as student group work, } \\
\text { professor support }\end{array}$ & \\
\hline & Support & 59 & $\begin{array}{l}\text { Codes such as guidance, professor } \\
\text { support, familial support }\end{array}$ & \\
\hline & Breadth of experience & 46 & $\begin{array}{l}\text { Codes such as academic experience, } \\
\text { jobs outside of physics }\end{array}$ & \\
\hline & $\begin{array}{l}\text { PER experience } \\
\text { (acceptance) }\end{array}$ & 46 & $\begin{array}{l}\text { Codes such as PER as a part of physics, } \\
\text { PER switched to, wanted Ph.D. in physics }\end{array}$ & \\
\hline & $\begin{array}{l}\text { Precollege science } \\
\text { experience }\end{array}$ & 40 & $\begin{array}{l}\text { Codes such as science in the home, science } \\
\text { in middle school, science in high school, } \\
\text { parent scientist }\end{array}$ & \\
\hline & Family & 23 & $\begin{array}{l}\text { Codes such as wants kids, family turmoil, } \\
\text { familial support }\end{array}$ & \\
\hline & Female camaraderie & 15 & $\begin{array}{l}\text { Codes such as female professor support, } \\
\text { female student support }\end{array}$ & \\
\hline & Career concerns & 8 & $\begin{array}{l}\text { Codes such as family and career, location, } \\
\text { teaching-intensive job, research-intensive } \\
\text { job }\end{array}$ & \\
\hline
\end{tabular}

also included many other codes, such as jobs outside of physics and research outside of physics. This transcript excerpt was coded as interests outside of physics because it describes an interest in spending time overseas (doing non-physics-related things) as well as an interest in choir:

I took a year off [after completing a bachelors in physics]... I went to Asia with my choir for three weeks and then stayed [over seas]... going and spending time overseas was more important to me than starting grad school (voice inflection) right away. So, I just said whatever, let's not think about it, I'll come back I'll work for a year and then I'll go to grad school....

Another example of an emergent theme was community. Community was formed from multiple codes including research advisor-good communication, worked on homework with other graduates, and friends with graduate students. Community was an emergent theme because it combined the previously mentioned codes to give them meaning together. In this case, the first author concluded that these positive experiences of graduate students in the above codes contributed to an overall positive community. Emergent themes helped to develop greater meaning within the data by combining the concrete experiences of participants into higher-level concepts.

Throughout the coding process the first author continually memoed his initial reactions to the data and shared these memos and thoughts with the other authors. The emerging codes, and emergent themes they then built, were discussed continually among us to determine what was important and informative about graduate students and postdoctoral scholars in PER.

The codes were used to gain an overall understanding of the experiences of these participants in PER. This was done by looking at individual codes and comparing them across participants. Within this process, common codes emerged as being important and salient to many of these participants, and some of these codes combined to form more overarching emergent themes that were important in addressing the third research question. Interpreted together, the combined set of codes and themes allowed us to answer the research questions. 
The trustworthiness of the analysis was ensured by following guidelines set forth by Lincoln and Guba [8]. Lincoln and Guba suggest four approaches to ensure trustworthiness: being in the setting for a long time, sharing data with participants, collecting multiple modes of data, and sharing data with colleagues [8]. The analysis presented above completed three of these suggestions completely and one partially. Respectively, the first author stayed at two of the campuses for a week and one for a weekend to become immersed in the setting, collected both self-reported demographic data and interviews, allowed for reflexive feedback from the participants on their interview transcripts, and discussed all results among the three researchers. The collection of multiple modes of data was difficult because the content of interviews surrounded participant's pasts. Consequently, the best approach to fulfill this suggestion was capturing data in the form of both demographics and their own interpretations of their lived experiences. Taking these steps helped to ensure the trustworthiness of the analysis and results.

\section{LIMITATIONS}

The limitations of this study include the small number of institutions sampled, one data point in the form of an interview per participant, and a small representation of graduate advisors $(N=10)$. Though these numbers are small, they do represent a wide range of experiences, personalities, and individual realities. The data points were also rich in stories, information, and perceptions of the PER community. They provide a range of pathways that can be examined for new information and lead future research into the community and graduate pathways of PER.
Another significant limitation is the sample used in this study. Participants in the study were all at three universities with well-established PER groups. A department that has a history of PER may create a different environment than a department where PER is relatively new, untested, and may not be seen as a part of physics. This idea emerged when one participant struggled to find acceptance of her work by the departmental graduate advisor as explained in the results below. The participant was a postdoctoral scholar at the time of this study and was the only participant who did her graduate PER work at a university that was not visited in this study.

\section{RESULTS}

In this section, we present the results to each of the four main research questions.

\section{A. Research question 1: When and how did these participants discover PER?}

Participants discovered PER at varying stages of their academic careers and in many different ways (see Table III). The code PER discovery was applied when participants discussed the time they discovered the field. These participants discovered PER at their undergraduate institutions $(N=5)$, during graduate school $(N=6)$, and as they were looking for a postdoctoral position $(N=1)$. One participant did not specify how they found out about PER, and could not be reached after the site visits. Participants' discovery of PER followed either formal pathways $(N=5)$ or informal pathways $(N=7)$ in their discovery. It is useful to delineate the discovery of PER between formal and informal pathways because they are

TABLE III. Participant discovery of PER.

\begin{tabular}{|c|c|c|c|c|c|}
\hline & & Total & $\begin{array}{c}\text { As an } \\
\text { undergraduate }\end{array}$ & $\begin{array}{l}\text { As a graduate } \\
\text { student }\end{array}$ & $\begin{array}{c}\text { As a } \\
\text { postdoctoral } \\
\text { scholar }\end{array}$ \\
\hline \multirow[t]{6}{*}{ Formal pathways } & & 5 & & & \\
\hline & Conference & & 1 & & \\
\hline & Campus talk & & 1 & & \\
\hline & Presentation to TAs or learning assistants & & & 1 & \\
\hline & National Teaching Fellowship Conference & & & 1 & \\
\hline & Advisor & & & 1 & \\
\hline \multirow[t]{7}{*}{ Informal pathways } & & 7 & & & \\
\hline & PER study participant & & 1 & & \\
\hline & Undergraduate grader for PER professor & & 2 & & \\
\hline & Heard about education group & & & 1 & \\
\hline & New faculty hire who was in PER & & & 1 & \\
\hline & $\begin{array}{l}\text { Found PER papers while looking at } \\
\text { teaching resources }\end{array}$ & & & 1 & \\
\hline & Searching for a postdoctoral program & & & & 1 \\
\hline Unknown & & 1 & & & \\
\hline Total & & 13 & 5 & 6 & 1 \\
\hline
\end{tabular}


created in different ways. The significant presence of informal pathways suggests that some of these students may not have discovered PER without chance.

Formal pathways involved official events during a student's life, such as meetings with an advisor, seminars, or conferences. Two participants discovered PER formally as undergraduates, one through a conference and one through a campus talk. In the excerpt below, a student describes discovering PER at a university talk:

... I was riveted and completely fascinated by everything he was talking about. Um and I think that's when it occurred to me that there was an entire field of research, not just teaching, but research that was dedicated to this sort of thing that I could go into.

Three participants also discovered PER through formal pathways after they were enrolled in a graduate program. These included a presentation to teaching assistants (TAs), a fellowship conference, and an advisor's advice. Below is an excerpt explaining how one participant found out about PER through her teaching fellowship program:

... before becoming a [program name] fellow I didn't realize that PER existed. ...one thing that really got me [in] to PER was [professor] was talking at the national academies, um about education issues and, and I was there and I was like the stuff he's talking about is fascinating!... so I looked into it a little more....

Informal pathways are more serendipitous occurrences such as word of mouth, having a new faculty member join the department, and finding PER while looking for resources to improve one's teaching. Three participants discovered PER informally as undergraduates. One was a participant in a PER study and two others were hired as undergraduate graders. According to one student:

...she [undergraduate advisor] said well you could try to get a job grading for a class... or you could get a job [teaching]... so I talked to [professor] who was an assistant research professor... he was actually one of my [professors]... and he agreed to let me do it. Both a little bit of research [PER] and teaching for money... I was just shocked at how much I liked it.

Three participants discovered PER through informal pathways as graduate students. These included hearing about a PER group, the department getting a new faculty hire, and discovering PER while looking for teaching resources. For example,

... so he [other graduate student teaching assistant] started this physics education forum... So I was starting to read more PER stuff... also took some education, graduate education courses.
Although the participants discovered PER in these ways, they did not necessarily choose to pursue the field at the same time. The following section will explore when and why the participants choose to pursue work in PER.

\section{B. Research question 2: When and why did these participants choose to do work in PER?}

\section{Time of choice of PER}

When participants discussed when they chose to pursue PER, the code time of choice was applied. Seven of the 13 participants chose PER as they were applying to graduate programs. These participants included the five who discovered PER as undergraduates, the one participant who discovered PER while in a teaching fellowship program, and the participant who did not specify the time of discovery. The two latter participants discussed above each had a master's degree, but then applied to other universities for graduate programs in PER. Thus, they were labeled as discovering PER in graduate school earlier in the paper. Two of the participants' experiences applying to graduate school are presented below. They wanted to study PER in graduate school and looked for schools with good programs. Their experiences are representative of students who chose the field during the application process of graduate school:

Primarily I was looking for... programs [while applying to graduate school] with an education research group... I was pretty sure at that point that that's what I wanted to do.

... I zoomed in on the [region]... and I looked for PER programs [while applying to graduate school].

The other six participants switched to PER when in graduate school $(N=4)$ or while searching for a postdoctoral position $(N=2)$. Below are examples of a graduate student and postdoctoral scholar, respectively, who switched into PER. Their experiences were similar to those of the other four switchers in this data set:

... it wasn't till I came out here [graduate school] that I kind of learned about PER and um got turned on to doing education research... .

Then I found out about a post-doc position in physics [education] at the [outreach museum], which was just up a couple hours away.

\section{Reason for choice of PER}

Each participant chose PER for their own unique reasons. However, the overall reasons for their choices can be reduced to three main codes (see Table IV): desire to help others or make an impact $(N=6)$, enjoyment of teaching 
TABLE IV. Participant choice of PER.

\begin{tabular}{|c|c|}
\hline $\begin{array}{l}\text { Chose PER for } \\
\text { Switched to PEI }\end{array}$ & $\begin{array}{l}\text { school } \\
\text { or after graduate school }\end{array}$ \\
\hline Time of choice & $\begin{array}{l}\text { As an undergraduate } \\
\text { As a graduate student } \\
\text { As a postdoctoral scholar }\end{array}$ \\
\hline Interest & $\begin{array}{l}\text { Teaching } \\
\text { Educational research } \\
\text { Help or impact people }\end{array}$ \\
\hline
\end{tabular}

aTwo participants previously had master's degrees but reapplied to new graduate programs for work in PER.

$(N=5)$, and enjoyment of educational research $(N=2)$. Some participants chose PER for a combination of these reasons, but they were coded for the main reason they discussed. This reason was decided by their own admission of importance or if the reason was discussed more often than the other reasons, as discerned by the first author.

The driving factor that brought six participants to PER was their desire to have an impact or help others. This code went beyond teaching, which is one way to help others, because participants explicitly explained that they wanted to make change. The following participant explained that they chose PER because it was emotionally fulfilling and that noneducation physics, to this participant, did not "spiderweb" into the rest of society:

It [non-education physics research] was intellectually interesting but also just kinda a closed system. It didn't seem to have any, it didn't seem to spiderweb out to the rest of society. It didn't seem to have much social value to me. Umm and since I'd been interested in education I actually taught some as an undergrad. I really enjoyed my TA-ing experience... Um so I talked to [PER professor] and then I went and talked to [PER professor] and I said you know I'm in [traditional area of physics] right now, but it's not really doing it for me emotionally.

The same participant went on to explain that teaching was a way to impact lives, and saw PER as an opportunity to teach. This shows the relationship between impact and teaching, although they are separate codes in this analysis:

I started to feel teaching would be a realistic way I could impact lives. I'd have teachers who would have an impact on me. I felt like if I could do that, I could feel good about, what I was doing. I needed that real purpose behind my life....

Another participant felt that noneducation physics could help people in the long run but not in a personal way. The thoughts of this participant are explained in the excerpt below:
I also just like that it's a field that can help people. That there is some sort of direct application to being able to help people in a personal way, rather than just, I mean I recognize that physics as a field often even basic research is helpful to people in the long run, but that's very removed um and that's not the focus and that's something that had bothered me a little bit throughout my career in physics. As much as I loved physics I definitely had my moments, I feel like this career path does not help people. This is not something that has direct application to the world's problems right now. I mean it does, but if you know what I mean, umm not in a tangible way. Uh, and education does....

In the aim of making an impact, one participant brought up the importance of equity and social justice. This participant explained that her original noneducation field of physics did not bring in these aspects:

[I was] very worried about issues of equity and inequality and things like that. And I realized that [non-education field of physics] wasn't getting me anywhere near any of that. In fact if anything it was probably going to contribute to people being able to [make money].

The following participant was pursuing graduate work in PER to have a larger impact than when the participant was teaching high school, by reaching more students nationally:

I think I can have a larger effect, even though I love being in the classroom, if I train future teachers and can advise on policy and so I ended up coming to get my degree, uh my PhD so that I could hopefully have a larger effect....

Five participants choose PER because of their interest in teaching. They gained this interest from varying types of experience with teaching. For some, it was through informal teaching experiences as they helped their friends prepare for an exam, and for others it was formally running a high school or undergraduate classroom, as either instructors or teaching assistants. Below are two excerpts from the interviews. The first is from a participant who taught formally at the college level and the second is from a participant who taught informally to peers:

Yeah I was a TA for two semesters and... I actually liked teaching quite a bit. I had a lot of fun with that... it was probably part of what got me interested in PER...

I thought it was really interesting working with students and... caring about what they were having trouble with and thinking about ways to help them... but I never really [knew] this would be something you could research.... 
The remaining two participants reported choosing PER because of their interest in educational research. One participant even explained that research is her favorite aspect of PER and that she did not look forward to teaching:

... the research has definitely [been] my favorite thing, without a doubt. I can't see that there are a lot of opportunities for me to do this type of research, other than in the university system. So it seems like academia would be the choice? But I don't particularly look forward to teaching.

\section{Research question 3: What were the participants' experiences in PER?}

The interviews revealed many participant experiences as they conducted work in PER and before they chose the field. Characteristics of these participants were highlighted from three emergent themes concerning their experiences. All three had codes that appeared in the most common codes table (Table II) and are important when describing the overall experience of graduate students in PER. The first of these emergent themes to be discussed is breadth of experience, the second is community, and the third is acceptance of PER.

\section{Breadth of experience}

Ten of the 13 participants had significant experiences outside of the field of physics, represented by the emergent theme breadth of experience. This is an emergent theme because it links together smaller codes, two of which appear in Table II (Breadth-Interests outside of physics and Breadth-Jobs outside of physics). These experiences varied from conducting research in a biology lab $(N=2)$ to having significant employment outside of the field of physics $(N=6)$. Two of the participants received their initial undergraduate degrees outside of physics before deciding on graduate school in the field. One held a degree in math and the other in a field of psychology:

So I was, my first undergraduate degree was in math. Umm and I did that mostly just because I enjoyed it. Didn't really have plans to do further research, or further study in that.

My undergraduate degree is actually in social psychology. So I started out as a physics major in college my first year, switched to social psychology after my second year and completed the bachelor's in social psychology, but by my senior year was back taking a whole bunch of physics. And continued to take a lot of calculus and science and stuff like that during the college years while I was studying social psychology.
Five of the participants, including the two above, had significant academic experience outside of physics. These went beyond taking a class or two outside of physics. They included research in the biological sciences or engineering, majoring in music, and pursuing an interest in journalism. The voices of the participants can be heard in the following excerpts:

... he set it up so that I could do research in [a] basic cancer research lab and then in a microbiology research $l a b . .$.

Well I actually ended up majoring in physics and nonprofessional music. They have a non-school of music music degree... and so I actually ended up doing that... Taking a lot of music history... and, um, so it was basically a balance of half of my classes were music and theory and composition and history and voice lessons kinda stuff and my other half of classes were upper level physics....

I found out about science writing and science journalism, and was like, oh, this is perhaps a really good meld with my interest in writing and communicationbecause I'd always been a good writer-and science. But, you know, I want to study science more first. So while I was in grad school, I took a journalism class, I started getting published in the local paper.

Four of the 13 participants lived and worked outside of the U.S. after getting their undergraduate degrees. They were all originally U.S. citizens. One participant followed a dream to enter the Peace Corps and explained:

I wanted adventure, wanted to learn more about the world. Intellectual curiosity... And I knew that once I launched into the Ph.D. program it was going to be harder to step away and take a break from the life trajectory.

Two found work in other countries as well, one in the field of physics and the other in the service sector. The last participant of these four traveled the world with a performance group.

\section{Community}

An important emergent theme that arose in this study was the community that students experienced in their research groups and departments. The emergent theme of community arose from three codes: participants who worked with other graduate students on homework $(N=8)$, the students who built meaningful friendships with other graduate students $(N=3)$, and those that reported having good communication with authors $(N=8)$. Community was an umbrella term for these three 
codes, which made it an emergent theme. Community itself also appears as a standard code in Table II, as it was specifically mentioned by several participants.

Eight of the 13 participants reported joining study groups to complete their homework. This is not necessarily a reflection of the PER community as their classmates would have come from many different disciplines. We inferred that this aspect potentially added to the overall sense of community these participants felt in graduate school. Some of the participants $(N=3)$ formed meaningful friendships from these study groups. The following is an excerpt from a participant who formed a friendship out of her study group:

Yeah I did [work with other students on homework]. I felt like I made some close friends pretty early... we all [lived] close by [each other]... [we would] meet up at [student's] house and talk over this homework, or study together for the exam....

Good communication with advisors was defined as continued in-person contact that was productive and pleasant. The latter of these may have made graduate students grow to expect positive interactions as they progressed in their field. These combined experiences fostered an overall positive climate. Campus climate has been described as practices by employees and students combined with their attitudes and beliefs [9]; this definition can easily be extended to the climate students experience with their research advisor.

One participant actually reported switching to PER because of the good climate and positive advisors. Below are excerpts from graduate students describing their relationships with advisors. Cumulatively, they painted a picture of advisors that are easy to get in contact with and able to help their graduate students. The provided excerpts all represent different advisors:

...[I have been] working directly with [advisor] since summer after my first year and [advisor] is a very busy guy, but he makes time for his graduate students and... his postdocs that he's working with... So he's very good about [setting a] weekly time to meet um which is good for me... I'm friends with a lot of grad students who have busy faculty who do a lot of traveling and have a lot of commitments and they don't feel like they get that... regular contact time... I feel like [advisor is] very actively involved in, in the research that I do. He's quick about providing feedback on stuff when I send it to him for editing....

... it's good I couldn't ask for a better advisor I really enjoy. So we meet once a week typically and then he's just right down the hall from me, so anytime I have pressing questions I can knock on the door. And he's always like yeah I got a minute... just can chat through this. He also tends to be a little hands-off. Umm, my personal project is very much my baby. He has had minimal impact on it in a lot of ways... so I more go to him when I need advice, and to sort of chat through either the physics of the certain thing or... the education aspect.

If I am on campus, I just go knock on his door um, if I'm at home I'd send him an email or send him a copy of what I'm working on... for feedback, and he is really good about getting back to me... if I'm in person he's almost always willing to say okay lets talk or um come back in this amount of time and we, I'll have time then. And over email he's pretty much always, I feel like he's just connected to his iPad anyways....

The relationships students formed with other students in and out of the classroom combined with the support of their research advisors created the emergent theme community. These aspects of their experiences in PER may have helped secure them in the field. However, coupled with this feeling of community was a latent hostility towards PER discussed by some participants, as discussed below.

\section{Acceptance of PER}

Six of the 13 participants' data exhibited codes that built the emergent theme acceptance of PER. This theme was composed of codes such as physics identity and discouragement to do PER. These issues of acceptance ranged from simple questions as to whether PER was a true subfield of physics, with no ramifications beyond a conversation, to one department's graduate advisor (not the student's research advisor) trying to prevent a PER student from graduating. In the excerpt below, one participant describes the issue of not being seen as a physicist. This excerpt represents the code physics identity:

... one thing is that I feel we all struggle with in the education research department is not being viewed as real physicists. Like for example I probably spent a lot more time than I should have in the last six months on this paper I was writing for the [journal] just because I wanted to have something outside of education...to show that I really do have like a good... grasp of physics....

Another participant was optimistic about PER's acceptance in her physics department. This participant was also adamant about her status as a physicist when discussing issues of acceptance and being a graduate student in PER. The following two quotes are both from the same participant:

I am optimistic about it. I feel like great strides have been made in the last decade as far as PER gaining 
acceptance... in the education community and in the physics community and I think that will continue... it's an uphill battle but I think we've gotten over the steepest part... I think ultimately that PER will eventually be fully incorporated into physics departments.

I'm trained as a physicist and I have a graduate level education as a physicist. I have taken as many physics courses... So my formal education physics is equal to anyone else's. The only difference between me and someone else will be that I did not do graduate level research in one particular field. So I have a hard time accepting that a person's focus on one particular aspect of physics... is the defining characteristic of a physicist. And if you want to call me not a physicist that's what you have to say, that's the only way you can do it. In my opinion. So yes absolutely [I] consider myself a physicist in many ways I would put my general knowledge of physics up against most of other graduate students, with no worries. Because I have spent a lot more time thinking about and focusing on general physics than they have. They may know one particular subtopic much much much much better than I do. But I think I know general physics better than they do.

Overall, the participants represented graduate programs in PER from five universities. Three of these universities are the visited institutions and two were represented by one postdoctoral scholar that attended them for graduate school. Of these five universities, two were described as having hostility towards physics Ph.D. work in PER. One participant in the study switched graduate schools during her career. At one institution the participant found a faculty supportive of PER, at another the participant found a faculty that housed members who even tried to stop her completion of a Ph.D. in PER:

[Institution 1] had no issues, they were cool. When I got to [institution 2], and I was doing education stuff, they were very traditional um so, they did not like that at all... But when we got to, to [institution 2] it was a big time struggle getting them to approve physics education as an aspect of, or a sub field of physics... I was constantly fighting, constantly fighting with one of the graduate advisors... But anytime I had to get anything filled out, I had to get his signature on the papers, because he was my graduate ya know advisor person, and every single time it was just a, just a hassle and a battle getting my, getting him to approve my committee because I had the Dean of the College of Education instead of a science person. Um so we had five professors and one who was the Dean of College of Education. I thought that would be cool, but he wasn't happy. Umm getting him to sign off on um, ya know that I had fulfilled my course work, getting him to sign off on my comprehensives, it was just, it was just a hassle.

\section{Research question 4: What are the career goals of these participants?}

The data collected within the code career goals highlights a few different paths these participants were interested in taking. Most participants expressed interest in pursuing a career in a tenure-track professorial position $(N=9)$. Of these, five specified a track at a research-intensive university, two in a teaching-intensive university, and two said either track was suitable for them. Below is an example of each career objective from three different participants:

Oh yeah! so I was just talking to someone about this the other day, and they were like 'why research one?' I think... there's a couple reasons that I think, that seems in my head to be good... I like research, I like to be supported. I don't really want to be just teaching classes, but I think I could do that already to a large degree... I would rather be doing like more research oriented things.

... small college, small university, that would be ideal and I would like to have the option of doing research if I would like to, but at the same time I'm fine with it in a teaching only position. I mean if it were a research only position, I probably wouldn't accept such a thing. I, I don't want to be a researcher; I don't enjoy that nearly as much as teaching.

I feel like I'm looking for some kind of faculty position where there's some balance of teaching and research where I can keep cranking out papers. . . if there's somewhere where I can serve in kind of a mentorship role for um graduate teachers, I think I'd really relish that.

Of the four remaining participants, two were in the process of creating their own careers, one by consulting and one by being hired as an educational researcher in a research group. Further details on their careers will not be discussed to protect their identities. The other two expressed interest in outreach as a career:

... I could go work at a museum, some place like the [outreach center] where I can still do research and do outreach, and still definitely be involved in an education but not in terms of like academia, university, position.

... [my] dream job would be to be in some sort of organizational level of a hands on museum kind of thing. Of a science museum....

\section{CONCLUSIONS AND DISCUSSION}

\section{A. Research question 1: Discovery of PER}

Seven of these participants in this study did not know about PER until they were in graduate programs $(N=6)$ or searching for a postdoctoral position $(N=1)$. The remaining six discovered PER as undergraduates $(N=5)$ 
or did not specify $(N=1)$. Seven participants discovered the field through informal pathways, such as their department happening to hire a PER professor or their participation in a PER research study. The other five found PER through formal pathways such as an advisor or conference talk. Of the undergraduate discoverers $(N=5)$, three actually conducted research in PER while completing their bachelor's degree and only two discovered the field through a formal pathway. Many participants began their work in PER as graduate students $(N=8)$ with the majority choosing the field while applying to these programs $(N=7)$; two other participants began conducting PER as postdoctoral scholars.

These results show that many of these participants were not aware of PER as undergraduates. If this is true of other students in physics, the field of PER may be at risk of losing potential scholars and bright minds. The field may benefit from efforts to expose more undergraduate physics majors to PER and having more readily available student research opportunities in PER. Some barriers in this process may be the lack of PER faculty in all physics departments and the latent hostility towards the field as a subject of physics, which was discussed by participants. Remedying these issues may require future research and substantial work.

\section{B. Research question 2: Choice of PER}

Approximately half of the participants $(N=7)$ chose PER before entering the graduate program where they completed their Ph.D. with a focus in PER. This shows that these scholars were aware of PER early in their academic careers. This may be different from the first generation of PER scholars, almost all of whom switched from other noneducation physics subfields [1,2], as did six participants in this study.

Six of the participants said they chose PER because they could help people or make an impact, the remaining participants enjoyed either teaching $(N=5)$ or educational research $(N=2)$. This range of reasons within these participants moved beyond a potential stereotype that scholars in PER prefer teaching to research. Of the 13 participants, only five explicitly chose PER because they enjoy teaching. The dominant trend was the motivation to have an impact on others. PER, to the participants who wanted to teach or make an impact, may have represented a way to humanize physics. They could involve themselves with people while staying in touch with the discipline they found fascinating. This may show that PER is a way for some scholars in the field to connect the abstract nature of physics with people and the larger world. This is a potentially important topic for future research.

\section{Research question 3: Experiences in PER}

The three emergent themes that were discussed within the experiences in PER results highlighted the positive aspects of PER that supported students in the classroom and in their research (community), looked at their diverse backgrounds (breadth of experience), and considered PER's acceptance within departments (acceptance). Of course, the support in the classroom was probably not specific to PER students since all the students in their classes were not in PER, but it did add to their overall sense of community.

What is important to focus on here are the facultystudent relationships. Eight participants spontaneously described a communicative and productive relationship with their research advisors. One student, as quoted previously, even explained that this experience was contrary to the experiences of many of her classmates in the department. Though it is impossible to expand this finding to other students in PER, this does suggest that PER may have scholars who actively promote the success of their students. This could come from their experiences with literature and course work in education that has given them more exposure on how to best work with students. Following previous results, though, if the advisors shared the same interest in having an impact or helping others as did these participants, they may be living out their ideals within their faculty-student relationships. Again, this is a potentially important topic for future research.

When considering the community, it is useful to point out the large number of women in the participant sample $(N=8)$, which was derived from a participant population that had more women than men ( 9 men, 10 women). This is in comparison to physics overall which only has an $18 \%$ representation of women at the graduate level [10]. It should be noted that all PER students and postdoctoral scholars were from the three visited universities that were invited to participate in the study - there was no effort to oversample women. The positive community reported by the women students did not differ from the men students. This is contrasted heavily by literature that suggests women often face chilly climates in physics $[11,12]$.

The experiences of participants, in this analysis, was not just limited to their PER-specific experiences. The majority of the participants demonstrated the emergent theme breadth of experience. They had significant non-physicsrelated experiences. This commonality is very interesting and may require further study. It is possible that the interdisciplinary nature of PER may draw in students with diverse backgrounds.

Finally, six of the participants discussed issues of acceptance of PER within their institutions. It is possible that if this trend holds true to more universities the field may still have a problem with being seen as a part of physics. However, of these six only two reported having faced hostility. The other four participants felt PER was allowed in their departments, but was questioned as to whether or not it was a "real" field of physics.

\section{Research question 4: Career trajectories}

Participants in this study overwhelmingly wanted to pursue a career in academia $(N=9)$. The majority of these students $(N=5)$ defined a research-intensive university to 
be their most desired path, while two others were considering it alongside a teaching-intensive university, with the remaining two wanting to work at a teaching-intensive school. Four students wanted to either do science outreach or create their own career entirely, which involved research to some extent. These participants represented a group of students strongly interested in scholastic endeavors and saw teaching and learning as a field of inquiry and not just a practice. Any potential stereotype that may paint PER scholars as teachers is not supported by the goals and aspirations expressed by these participants.

\section{E. Final thoughts}

The results of this study suggest that further attention needs to be placed on the recruitment of undergraduate students. For the field to sustain itself, a strong pipeline of future scholars must be developed who are fluent in both physics content knowledge and educational research methodology. Future research may be able to tackle these issues by developing a stronger model for recruitment of graduate students into PER and raising awareness about the field to undergraduates. In addition, this study suggests that exploration into the attributes of PER that seem to attract more women than traditional fields of physics may shed light on the overall gender gaps present in physics programs and how to alleviate them. Finally, PER was a way for some of the participants to make an impact. By highlighting this aspect to undergraduate students, it may be possible to capture new minds into the field who may have not considered it otherwise.

Future work investigating the experiences and career pathways of students and scholars in PER will need to collect data on a larger scale. If additional research can show that PER does truly have more gender diversity and a stronger community than other fields of physics, these findings may be useful in support and promotion of the field. An initiative by the first and second authors has already begun to collect data on graduate students in PER using a comprehensive Email list created for the first election of The Physics Education Research Consortium of Graduate Student (PERCoGS). This study will assess the demographics and climate issues in physics, and survey items were informed by the results of this project.

Overall, the participants described a positive climate and enjoyable graduate experience alongside productive and communicative relationships with their advisors. Their stories highlight their PER groups as scholars that have created a substantial and meaningful community within their institutions. If this trend holds true for PER groups at other institutions, it may be possible to study PER and derive best practices of community building and graduate student relationships that could be effective in the physics community at large.

\section{ACKNOWLEDGMENTS}

The authors would like to thank the Michigan Space Grant Consortium and the Michigan Advancement for Graduate Education and the Professoriate (AGEP) Alliance for their financial and professional support. They would also like to thank the Physics Education Research Leadership and Organization Council for funding this project with a PERLOC mini grant.

\section{APPENDIX: DEMOGRAPHICS QUESTIONNAIRE}

\section{Name:}

Year in graduate school:

Degree sought (e.g. MS, PhD, EdD):

Research Subfield (e.g. Astronomy, PER, Nuclear Physics):

Undergraduate Degree (e.g. physics, math, astronomy):

1. Are you a full time or part-time student?

2. What phase are you at in your graduate work? (e.g. course work, proposal, dissertation)?

3. Have you passed your qualifying exams, or the equivalent at your institution?

4. How are you funded (e.g. teaching assistantship, research appointment)?

5. Are you a citizen of the United States of America? If not, where are you a citizen?

6. Where were you born?

7. What is the highest education received by your father?

8. What is the highest education received by your mother?

9. Is there anything else you would like to add about yourself?

Age:

Race:

Ethnicity:

Birth sex (e.g. male, female, intersex, other):

Gender identity (e.g. male, female, other):

Sexual orientation (e.g. heterosexual, gay, lesbian, other):

Disability (yes/no, e.g. cognitive, physical): 
[1] R. J. Beichner, An introduction to physics education research, in Getting Started in Physics Education Research, edited by C. Henderson and K. A. Harper (American Association of Physics Teachers, College Park, MD, 2009).

[2] National Research Council, Discipline-Based Education Research: Understanding and Improving Learning in Undergraduate Science and Engineering (National Academies Press, Washington, DC, 2012).

[3] http://www.compadre.org/PER/programs/.

[4] C. Marshall and G.B. Rossman, Designing Qualitative Research (Sage Publications, Thousand Oaks, CA, 2011), 5 th ed.

[5] J.W. Creswell, Qualitative Inquiry \& Research Design: Choosing Among Five Approaches (Sage Publications, Thousand Oaks, CA, 2007).

[6] J.C. Hermanowicz, Live In Science: How Institutions Affect Academic Careers (University of Chicago Press, Chicago, 2009).
[7] K. Charmaz, Constructing Grounded Theory (Sage Publications, Thousand Oaks, CA, 2006).

[8] Y.S. Lincoln and E. Guba, Naturalistic Inquiry (Sage Publications, Beverly Hills, CA, 1985).

[9] S. Rankin and R.D. Reason, Transformational tapestry model: A comprehensive approach to transforming campus climate, J. Diversity Higher Educ. 1, 262 (2008).

[10] American Institute of Physics, Statistical Research Center, http://www.aip.org/statistics/.

[11] C. Hollenshead, P. S. Younce, and S. A. Wenzel, Women graduate students in mathematics and physics: Reflections on success, J. Women Minorities Sci. Eng. 1, 63 (1994).

[12] J. M. Curtin, G. Blake, and C. Cassagnau, The climate for women graduate students in physics, J. Women Minorities Sci. Eng. 3, 95 (1997). 